men aged 25-64 years old at 3 time points (1984, 1988 and 1994). Total sample was 2149 persons. The period of study was 10-20 years. Incident cases of AH were counted and Spilberger's test for estimation of personal anxiety (PA) was used. Coxproportional regression model was used for an estimation of RR.

Results During 20 years of investigation the incidence of $\mathrm{AH}$ was $16.9 \%$. High levels of personal anxiety (HLA) were present in $57.4 \%$ of the group with incident $\mathrm{AH}$. Incident $\mathrm{AH}$ with HLA was significantly higher in several subgroups: single, divorced and widowed men; incomplete secondary and primary education; men undertaking hard physical work. The RR of $\mathrm{AH}$ development during the first 5 years of observation in the HLA group compared to average level of anxiety (ALA) was 6.8 times higher (95\% CI 3.2 to 14.2; $\mathrm{p}<0.05$ ); in 10 years the risk was 5.0 times higher $(95 \%$ CI 2.9 to $11.8 \mathrm{p}<0.05)$ higher, and in 20 years it was 1.8 times higher $(95 \% \mathrm{CI}$ 1.1 to $3.2 \mathrm{p}<0.05)$.

Conclusion Personal anxiety should be considered in the development of $\mathrm{AH}$.

\section{P1-158 POLISH SURGICAL STAFF AND POST-VACCINATION TESTING TO DOCUMENT IMIMUNITY AFTER HBV VACCINATION: A CROSS-SECTIONAL SEROSURVEY}

doi:10.1136/jech.2011.142976d.51

${ }^{1}$ M Ganczak, ${ }^{*}{ }^{1}$ Z Szych, ${ }^{2}$ M Korzeń. ${ }^{1}$ Pomeranian Medical University, Szczecin, Poland; ${ }^{2}$ Westpomeranian University of Technology, Szczecin, Poland

Hepatitis B vaccination is recommended for HCWs but has a nonresponse rate of $5 \%-32 \%$. In Poland there is no standardised postvaccination protocol to confirm immunity.

Objective To determine the fraction of those who were previously vaccinated but not checked for serologic evidence of hepatitis B immunity and to assess anti-HBs levels in that group by an anonymous cross-sectional sero-survey.

Methods surgical staff from 16 randomly selected hospitals in West Pomerania, Poland surveyed July 2010-January 2011.

Results of 488 participants (49 males, 439 females, Me age 42 years), in $361(74.0 \%$; $95 \%$ CI 69.9 to $77.7 \%)$ anti-HBs status was not determined after the basic course of HBV vaccination. Five per cent of those showed anti-HBs titre of $0.0 \mathrm{mIU} / \mathrm{ml}$ ( 6 of 9 given booster doses developed anti-HBs $>10 \mathrm{mIU} / \mathrm{ml}$ ) and $7.2 \%$ showed anti-HBs titre of $0.1-10 \mathrm{mIU} / \mathrm{ml}$. The multivariate logistic regression model revealed that working in a teaching hospital was associated with a smaller odds of not being checked for serologic evidence of immunity after $\mathrm{HBV}$ vaccination (OR 0.22 , 95\% CI 0.14 to 0.35 ; $\mathrm{p}<0.0001)$.

Conclusions The majority of surgical staff do not confirm immunity after the basic course of HBV immunisation. Working in other than teaching hospital is related to increased odds of not confirming immunity. It is unclear whether $5 \%$ surveyed who showed no serologic evidence of hepatitis B immunity are non-responders, lost immunity, or retained anamnestic potential. Lack of booster vaccination response in 3/9 subjects suggests non-responders Therefore, strict post-vaccination testing to document immunity is crucial to detect non-responders among surgical staff constantly exposed to blood.

\section{P1-159 INCOME AND ACCESS TO MEDICINES IN BRAZIL, 2008-2009}

doi:10.1136/jech.2011.142976d.52

L Garcia,* A Pacheco, L Santana, L C Magalhães, M Stivali, C Santos. Institute for Applied Economic Research (IPEA), Brasilia, Distrito Federal, Brazil

Introduction The Brazilian healthcare system is universal and provides pharmaceutical assistance. This paper investigates income disparities in public provision and out-of-pocket spending on medicines in Brazil.

Methods Prevalence of public provision was estimated using data from the National Household Sample Survey (PNAD-2008) (99\% CIs). The mean spending of families on medicines (Brazilian Real-R\$) and the proportion of this spending in relation to the family income were estimated using data from the Family Budget Survey (POF-2008/2009). Samples were divided in deciles of monthly family income per-capita.

Results Among people who had a drug prescription in the 2 weeks preceding the interview, $45.8 \%(45.5 \%-47.1 \%)$ received all or part of the medicines without paying, $62.9 \%(60.3 \%-65.4 \%)$ in the bottom income decile, and $15.8 \%(14.1 \%-17.7 \%)$ on the top. Among those who reported life-long use of medicines, $51.6 \%(51.1 \%-52.1 \%)$ received part or all without paying, $66.2 \%(63.9 \%-68.3 \%)$ in the bottom decile, and $17.8 \%(16.8 \%-18.9 \%)$ on the top. The mean monthly per-capita spending on medicines was $\mathrm{R} \$ 4.42$ in the bottom decile and $\mathrm{R} \$ 58.11$ on the top.

Conclusion While the public provision of medicines was about four times higher in the bottom decile than in the top and the out-ofpocket spending was 13 times higher in the top decile, the proportion of spending on medicines in relation to the family income was three times higher in the bottom decile. Although the public policy is equitative, the burden of spending on medicines is too high on poorer families.

\section{P1-160 HEALTHCARE EXPENDITURE IN THE LAST YEARS OF LIFE FOR OUT-OF-HOSPITAL MEDICARE BENEFITS SCHEDULE FUNDED SERVICES IN WESTERN AUSTRALIA: A POPULATION-BASED DATA LINKAGE STUDY}

doi:10.1136/jech.2011.142976d.53

${ }^{1,2} \mathrm{R}$ Moorin, ${ }^{1} \mathrm{D}$ Gibson, ${ }^{*}{ }^{1} \mathrm{D}$ ' A Holman. ${ }^{1}$ Curtin University, Perth, Western Australia, Australia; ${ }^{2}$ University of Western Australia, Perth, Western Australia, Australia

Introduction Persistent debate over the relationship between timeto-death, age and healthcare expenditure may be the result of overgeneralised modelling. Single-population total health service utilisation models may not take into account differing patterns of use between out-of-hospital services. We explored the relationship between time-to-death, age and healthcare expenditure for government funded out-of-hospital services in last years of life to determine effects of service type and the stability of this relationship over time.

Methods Records of all deaths in Western Australia from 1990 to 2004 extracted from the mortality register and linked to records from the Medicare Benefit Scheme. Claims 5 years prior to death were identified from all Medicare Benefit Scheme claims originating in Western Australia between 1984 and 2004. Out-ofhospital costs were assigned to all services within 5 years of death from five major causes using Medicare Benefit Scheme costing information.

Results Out-of-hospital healthcare expenditure increased for primary care services during last 2 months of life. A similar trend was observed in specialist services and diagnostic and therapeutic services, however an earlier increase in expenditure occurred during the penultimate year before death.

Conclusion Primary care service cost patterns varied for specialist services and diagnostic and therapeutic services for both time to death and age. Significant differences in relationship between time to death, age and healthcare expenditure were identified between service types, highlighting potential shortcomings in using single population models to predict future healthcare expenditure. 